\title{
Angioplasty and stenting for a young stroke patient diagnosed as cerebrovascular fibromuscular dysplasia
}

\author{
Jia-Ping Xu, Yong-Jun Cao, Guo-Dong Xiao, Chun-Yuan Zhang, Ji-Jun Shi \\ Department of Neurology, The Second Affiliated Hospital of Soochow University, Suzhou 215004, Jiangsu, China.
}

\section{A B S T R A C T}

Fibromuscular dysplasia (FMD) is a noninflammatory, nonatherosclerotic, and multifocal vascular disease, commonly involving the cerebral and renal arteries. Cerebrovascular stenosis and spontaneous dissection resulting from cerebrovascular FMD (cFMD) is one of the important causes of young stroke. Here, we reported the case of cFMD in a 28-year-old male patient with stroke. Digital subtraction angiogram demonstrated a dissecting aneurysm in the carotid artery and multiple stenoses in both vertebral arteries. Endovascular angioplasty with balloon predilation and stenting was successfully performed for the patient when the medical treatment was not adequate. The follow-up showed a remarkable improvement and no recurrence of stroke.

Key words: Angioplasty, fibromuscular dysplasia, stent, therapy, young stroke

\section{INTRODUCTION}

Fibromuscular dysplasia (FMD) is an uncommon vascular disease that occurs more often in young women. FMD mainly involves the renal and cerebral arteries. ${ }^{[1]}$ Cerebrovascular FMD (cFMD) can be complicated by stroke and associated with headaches, and it can also be associated with intracranial aneurysms with a high risk of subarachnoid hemorrhage. The cerebrovascular stenosis and dissection, as a result of FMD, is one of the important causes of stroke in the young (15-45-year-old). A case report of cFMD treated with angioplasty and stenting in a young male patient is presented, along with an overview of the available literature.

\section{CASE REPORT}

A 28-year-old male patient was admitted to our stroke unit ward of Department of Neurology in the Second

Corresponding Author: Dr. Ji-Jun Shi,

Department of Neurology, The Second Affiliated

Hospital of Soochow University, No. 1055,

Sanxiang Road, Suzhou 215004, Jiangsu, China.

E-mail: shijiiun2008@126.com

\begin{tabular}{|l|l|}
\hline \multicolumn{2}{|c|}{ Access this article online } \\
\hline Quick Response Code: & \\
\hline & Website: \\
\hline & Www.nnjournal.net \\
\cline { 2 - 3 } & \\
\hline
\end{tabular}

Affiliated Hospital of Soochow University because of ischemic stroke with inarticulate speech and paralysis of right limbs. The patient had no medical history of traditional cerebrovascular risk factors, like hypertension. The patient also had no personal or family history of stroke. The dysphasia and slight right-sided weakness occurred without the definite causes for 1-day before the admission without any prior warning. Magnetic resonance imaging revealed a new infarction lesion on the left temporal lobe and occlusion of the left internal carotid artery (ICA). The ultrasound sonography also demonstrated the occlusion in the left ICA. Antiplatelet (clopidogrel $75 \mathrm{mg}$ and aspirin $100 \mathrm{mg}$ q.d. p.o.), and statin therapy (atorvastatin $40 \mathrm{mg}$ q.n. p.o.) were given to this patient, diagnosed as acute cerebral infarction without a clear etiology. During this hospitalization for 7 days, logaphasia, and more severe paralysis of the right limbs occurred. Then, he was transferred to our stroke unit ward for further vascular evaluation and interventional therapy. The positive neurological signs were as follows: incomplete logaphasia, central facial paralysis, right-sided hemiparesis (4/5), and positive Babinski sign. Other

This is an open access article distributed under the terms of the Creative Commons Attribution-NonCommercial-ShareAlike 3.0 License, which allows others to remix, tweak, and build upon the work non-commercially, as long as the author is credited and the new creations are licensed under the identical terms.

For reprints contact: nn_editor001@nnjournal.net

Cite this article as: Xu JP, Cao YJ, Xiao GD, Zhang CY, Shi JJ. Angioplasty and stenting for a young stroke patient diagnosed as cerebrovascular fibromuscular dysplasia. Neuroimmunol Neuroinflammation 2015;2:291-4. Received: 08-06-2015; Accepted: 06-08-2015 
laboratory tests about thyroid function, autoimmune antibodies, and vasculitis indicators were all normal.

Digital subtraction angiography (DSA) showed a dissecting aneurysm of the C1 segment of right ICA and subtotal occlusion of the left ICA [Figure 1a and b]. Anterior communicating artery was open, and the left middle cerebral artery (MCA) territory got collateral blood flow from the right MCA [Figure 1c]. Severe bilateral stenosis ( $>70 \%$ ) was also revealed on the V2 segment of both vertebral arteries (VA) [Figure 1d-f]. Then angioplasty and stenting was performed for this young patient.

First, the vertebral angioplasty and stenting was performed and then the left ICA was stented because of the carotid sinus reaction. A dissecting stenosis on the initial segment of the left VA stenosis was found during the angiography before stenting. Firstly, one expanding stent was placed on the dissecting site, and then another two stents $(4 \mathrm{~mm} \times 60 \mathrm{~mm}$ and $4 \mathrm{~mm} \times 40 \mathrm{~mm}$ ) were delivered and deployed to cover the long stenotic lesion. A final angiography demonstrated an excellent stent placement across the stenotic lesion of the left VA and left vertebral angiogram revealed a good flow in vertebral and basilar arteries [Figure 1g].

After advancing the $8 \mathrm{~F}$ guiding catheter within the C1 segment of the left ICA, a microwire $(0.014$ inches) was delivered through the subtotal occlusive site and predilation was performed with a balloon $(2.5 \mathrm{~mm} \times 15 \mathrm{~mm})$ at $6 \mathrm{~atm}$. Then, the stent ( $4 \mathrm{~mm} \times 40 \mathrm{~mm}$ Xpert Stent System) was deployed over the stenosis and postdilation was performed with a balloon at $6 \mathrm{~atm}$. Angiography after stenting showed the revascularization of the subtotal stenosis and good flow across the stent with complete disappearance of this stenosis [Figure $1 \mathrm{~h}$ ]. After the procedure, antiplatelet therapy (clopidogrel $75 \mathrm{mg}$ and aspirin $100 \mathrm{mg}$ daily) was sequentially administered for 3 months, and then aspirin is taken prophylactically. During the follow-up period of 3 years, this patient was normal at 3 months after discharged from our hospital, and no recurrent stroke occurred.

\section{DISCUSSION}

FMD is a noninflammatory, nonatherosclerotic vascular disease that commonly involves the renal and internal carotid arteries. The young patient has multiple vascular stenoses, but no cerebrovascular risk factors; therefore, cFMD can be diagnosed. The prevalence of symptomatic renal artery FMD is about 4 in 1000, and the prevalence of cFMD is probably half that. ${ }^{[1-4]}$ FMD usually affects the females from 15 to 50 years of age and accounts for around $10 \%$ of cases of renal artery stenosis. $^{[1-4]}$

Although the etiology of FMD is not well understood, several mechanisms have been proposed. For example,
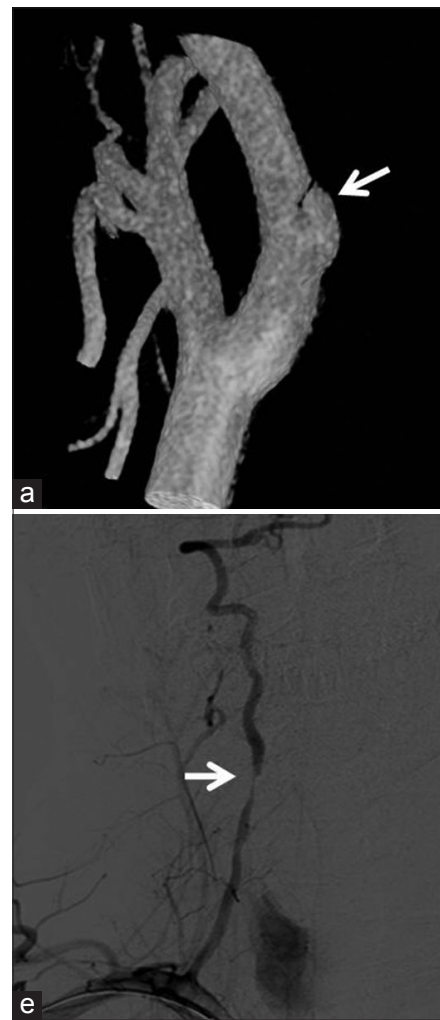
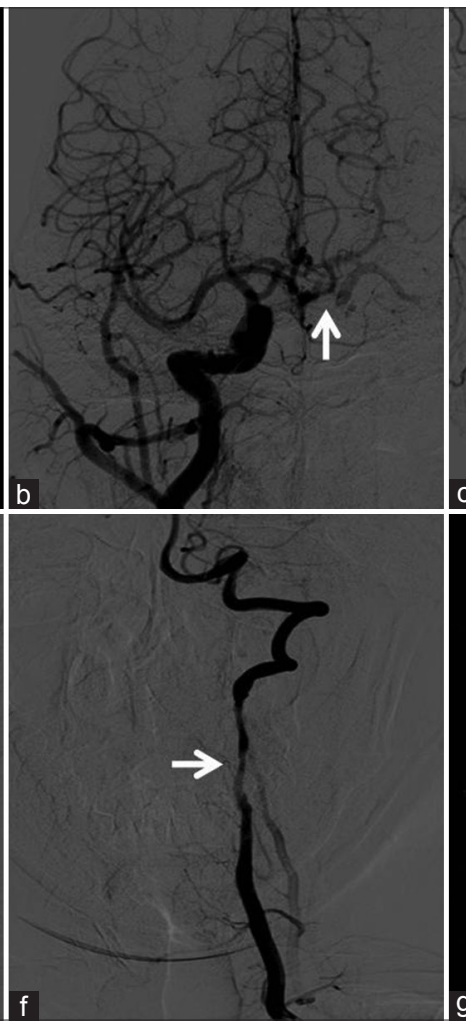
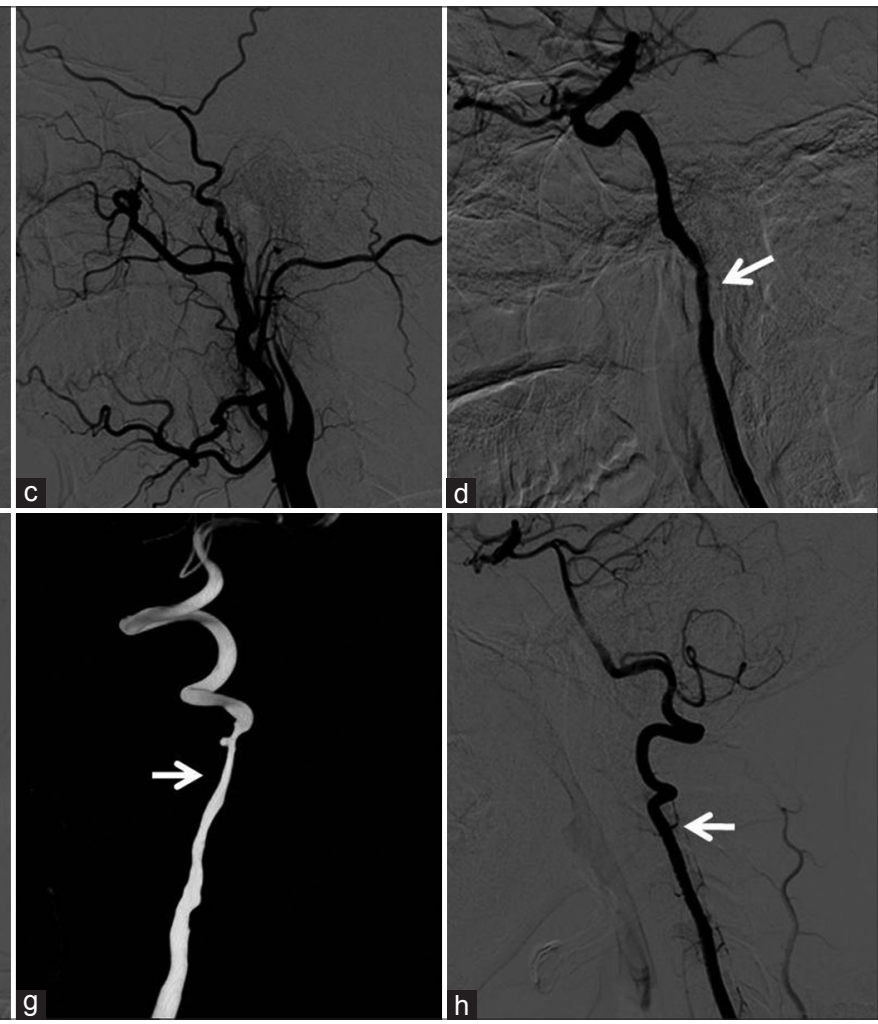

Figure 1: (a) The dissecting aneurysm on the C1 segment of right internal carotid artery; (b) "rat tail sign" of the left internal carotid artery before predilation; (c) the anterior communicating artery was open and the left middle cerebral artery territory got collateral blood flow from the right middle cerebral artery; (d-f) severe bilateral stenosis on the V2 segment of both VAs; (g) left vertebral arteries after stenting; (h) left internal carotid artery after balloon predilation 
genetic predisposition, hormonal factors, and arterial wall ischemia. ${ }^{[1,4]}$ The pathogenesis of FMD remains unclear. A number of theories have been proposed, including the environmental factors such as smoking and estrogen, as well as genetic factors; however, about $10 \%$ of patients with FMD have an affected family member. ${ }^{[5]}$

cFMD may be asymptomatic or associated with a variety of nonspecific symptoms, including headache, tinnitus, vertigo, lightheadedness, and syncope..$^{[1]}$ The clinical manifestations of cFMD are variable and depend on a number of factors, including the distribution of vascular bed involvement and the type and severity of the vascular lesions. ${ }^{[6,7]}$ The more specific neurologic syndromes of TIA, amaurosis fugax, stroke, Horner's syndrome, and cranial-nerve palsies may be the first presentation of FMD involving the carotid or VA. ${ }^{[8]}$ And the most feared and serious sequela of CFMD include TIA, stroke, subarachnoid hemorrhage, and cervical artery dissection. It shows that FMD is present in about $15-20 \%$ of patients with a spontaneous dissection of carotid or VA. ${ }^{[9]}$ And multiple cervical artery dissections are more common in patients with an underlying arteriopathy, such as FMD. ${ }^{[10]}$

Noninvasive imaging modalities for diagnosing FMD include Doppler ultrasound, computed tomographic angiography, and magnetic resonance angiography. The accepted gold standard for the diagnosis of cFMD is DSA. "String of beads pattern" in the pathological carotid or renal arteries is an important and most common angiographic finding and is present in over $90 \%$ of cases. However, it was not observed in this present case. This invasive test should be considered for those symptomatic patients in whom intervention is contemplated or for cases in which there is uncertainty about the patient's diagnosis or severity of the disease. ${ }^{[11]}$

Medical therapy and revascularization are the two major treatment options for cFMD patients. As previously discussed, antiplatelet therapy is the mainstay of the medical therapy. For symptomatic patients with carotid or vertebral artery FMD, who have suffered a dissection, angioplasty with stenting may be performed. The indications for intervening in cFMD are for those in whom antiplatelet or anticoagulant therapy is contraindicated or less effective and for those cFMD patients with pseudoaneurysm formation, usually the result of a prior dissection. ${ }^{[12]}$

The patient was successfully treated with angioplasty with stenting. During the follow-up period, no adverse events and complications were observed suggesting that angioplasty with stenting may be a safe and effective treatment method for this condition.

\section{Financial support and sponsorship}

This study was supported by the National Natural Science Foundation of China (Grant No. 81471195) and the second affiliated hospital of Soochow university preponderant clinic discipline group project funding (Grant No. XKQ2015002).

\section{Conflicts of interest}

There are no conflicts of interest.

\section{REFERENCES}

1. Slovut DP, Olin JW. Fibromuscular dysplasia. N Engl J Med 2004;350:1862-71

2. Plouin PF, Perdu J, La Batide-Alanore A, Boutouyrie P, Gimenez-Roqueplo AP, Jeunemaitre X. Fibromuscular dysplasia. Orphanet J Rare Dis 2007;2:28.

3. Shejul YK, Viswanathan MK, Jangale P, Kulkarni A. Fibromuscular dysplasia: a cause of secondary hypertension. Korean J Intern Med 2014:29:840-1.

4. Mettinger KL. Fibromuscular dysplasia and the brain. II. Current concept of the disease. Stroke 1982;13:53-8.

5. Poloskey SL, Olin JW, Mace P, Gornik HL. Fibromuscular dysplasia. Circulation 2012;125:e636-9.

6. Olin JW, Froehlich J, Gu X, Bacharach JM, Eagle K, Gray BH, Jaff MR, Kim ES, Mace P, Matsumoto AH, McBane RD, Kline-Rogers E, White CJ, Gornik HL. The United States Registry for Fibromuscular Dysplasia: results in the first 447 patients. Circulation 2012;125:3182-90.

7. Sharma AM, Kline B. The United States registry for fibromuscular dysplasia: new findings and breaking myths. Tech Vasc Interv Radiol 2014;17:258-63

8. Mettinger KL, Ericson K. Fibromuscular dysplasia and the brain. I Observations on angiographic, clinical and genetic characteristics. Stroke 1982;13:46-52.

9. Divjak I, Slankamenac P, Jovicevic M, Zikic TR, Jesic A. Diagnosis and outcome of cervical artery dissection. Med Pregl 2011;64:392-6.

10. Bejot Y, Aboa-Eboule C, Debette S, Pezzini A, Tatlisumak T, Engelter S, Grond-Ginsbach C, Touze E, Sessa M, Metso T, Metso A, Kloss M, Caso V, Dallongeville J, Lyrer P, Leys D, Giroud M, Pandolfo M, Abboud S'CADISP Group. Characteristics and outcomes of patients with multiple cervical artery dissection. Stroke 2014; $45: 37-41$

11. Olin JW, Gornik HL, Bacharach JM, Biller J, Fine LJ, Gray BH, Gray WA, Gupta R, Hamburg NM, Katzen BT, Lookstein RA, Lumsden AB, Newburger JW, Rundek T, Sperati CJ, Stanley JC, American Heart Association Council on Peripheral Vascular Disease; American Heart Association Council on Clinical Cardiology; American Heart Association Council on Cardiopulmonary; Critical Care, Perioperative and Resuscitation; American Heart Association Council on Cardiovascular Disease in the Young; American Heart Association Council on Cardiovascular Radiology and Intervention; American Heart Association Council on Epidemiology and Prevention, American Heart Association Council on Functional Genomics and Translational Biology; American Heart Association Council for High Blood Pressure Research; American Heart Association Council on the Kidney in Cardiovascular Disease; American Heart Association Stroke Council. Fibromuscular dysplasia: state of the science and critical unanswered questions: a scientific statement from the American Heart Association. Circulation 
2014;129:1048-78.

12. Kernan WN, Ovbiagele B, Black HR, Bravata DM, Chimowitz MI, Ezekowitz MD, Fang MC, Fisher M, Furie KL, Heck DV, Johnston SC, Kasner SE, Kittner SJ, Mitchell PH, Rich MW, Richardson D,
Schwamm LH, Wilson JA. Guidelines for the prevention of stroke in patients with stroke and transient ischemic attack: a guideline for healthcare professionals from the American Heart Association/ American Stroke Association. Stroke 2014;45:2160-236. 